\title{
Foreign direct investment and economic growth in Malaysia: the role of domestic financial sector
}

\begin{abstract}
This study aims to incorporate the role of domestic financial system in transferring the technological diffusion embodied in FDI inflows on the Malaysian economy from 1970ï 2001. Applying bound test, or unrestricted error correction model (UECM) proposed by Pesaran et al. (2001), the presence of FDI inflows creates a positive technological diffusion in both short- and long-run if the evolution of domestic financial system has achieved a certain minimum level. This implies that the improvement of technology level in Malaysia in the long run is due to the spillover efficiency effects from FDI. Hence, the study suggests that FDI tends to be more likely to enhance economic growth more efficiently when a recipient country has a well-developed and well-functioning financial sector.
\end{abstract}

Keyword: Financial development; Foreign direct investment; Economic growth; Bound test; Technological diffusion 